\title{
PRIMMO study protocol: a phase II study combining PD-1 blockade, radiation and immunomodulation to tackle cervical and uterine cancer
}

Sandra Tuyaerts ${ }^{1,2^{*}}$ (D) An M. T. Van Nuffel ${ }^{3}$, Eline Naert ${ }^{4,5}$, Peter A. Van Dam ${ }^{6}$, Peter Vuylsteke ${ }^{7}$, Alex De Caluwé ${ }^{8}$, Sandrine Aspeslagh ${ }^{8}$, Piet Dirix ${ }^{9,10}$, Lien Lippens ${ }^{4,5}$, Emiel De Jaeghere ${ }^{4,5}$, Frédéric Amant ${ }^{1,2,11,12}$, Katrien Vandecasteele $e^{5,13+}$ and Hannelore Denys $s^{4,5^{*}+}$

\begin{abstract}
Background: Immunotherapeutic approaches have revolutionized oncological practice but are less evaluated in gynecological malignancies. PD-1/PD-L1 blockade in gynecological cancers showed objective responses in 13-17\% of patients. This could be due to immunosuppressive effects exerted by gynecological tumors on the microenvironment and an altered tumor vasculature. In other malignancies, combining checkpoint blockade with radiation delivers benefit that is believed to be due to the abscopal effect. Addition of immune modulation agents has also shown to enhance immune checkpoint blockade efficacy. Therefore we designed a regimen consisting of PD-1 blockade combined with radiation, and different immune/environmental-targeting compounds: repurposed drugs, metronomic chemotherapy and a food supplement.

We hypothesize that these will synergistically modulate the tumor microenvironment and induce and sustain an anti-tumor immune response, resulting in tumor regression.

Methods: PRIMMO is a multi-center, open-label, non-randomized, 3-cohort phase 2 study with safety run-in in patients with recurrent/refractory cervical carcinoma, endometrial carcinoma or uterine sarcoma.

Treatment consists of daily intake of vitamin D, lansoprazole, aspirin, cyclophosphamide and curcumin, starting 2 weeks before the first pembrolizumab dose. Pembrolizumab is administered 3-weekly for a total of 6 cycles. Radiation ( $3 \times 8 \mathrm{~Gy})$ is given on days 1,3 and 5 of the first pembrolizumab dose.

The safety run-in consists of 6 patients. In total, 18 and 25 evaluable patients for cervical and endometrial carcinoma respectively are foreseen to enroll. No sample size is determined for uterine sarcoma due to its rarity. The primary objective is objective response rate at week 26 according to immune-related response criteria. Secondary objectives include safety, objective response rate at week 26 according to RECIST v1.1, best overall response, progression-free survival, overall survival and quality of life.

Exploratory, translational research aims to evaluate immune biomarkers, extracellular vesicles, cell death biomarkers and the gut microbiome.

(Continued on next page)
\end{abstract}

\footnotetext{
* Correspondence: sandra.tuyaerts@kuleuven.be; hannelore.denys@uzgent.be

${ }^{+}$Katrien Vandecasteele and Hannelore Denys contributed equally to this

work.

'Division of Gynecologic Oncology, Department of Oncology, KU Leuven,

Leuven, Belgium

${ }^{4}$ Division of Medical Oncology, UZ Gent, Ghent, Belgium

Full list of author information is available at the end of the article
}

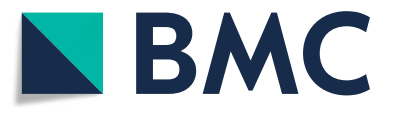

(c) The Author(s). 2019 Open Access This article is distributed under the terms of the Creative Commons Attribution 4.0 International License (http://creativecommons.org/licenses/by/4.0/), which permits unrestricted use, distribution, and reproduction in any medium, provided you give appropriate credit to the original author(s) and the source, provide a link to the Creative Commons license, and indicate if changes were made. The Creative Commons Public Domain Dedication waiver (http://creativecommons.org/publicdomain/zero/1.0/) applies to the data made available in this article, unless otherwise stated. 
(Continued from previous page)

Discussion: In this study, a combination of PD-1 blockade, radiation and immune/environmental-targeting compounds is tested, aiming to tackle the tumor microenvironment and induce anti-tumor immunity. Translational research is performed to discover biomarkers related to the mode of action of the combination.

Trial registration: EU Clinical Trials Register: EudraCT 2016-001569-97, registered on 19-6-2017. Clinicaltrials.gov: NCT03192059, registered on 19-6-2017.

Keywords: PD-1 blockade, Radiation, Immune modulation, Tumor microenvironment, Cervical carcinoma, Endometrial carcinoma, Uterine sarcoma, Drug repurposing, Metronomic chemotherapy, Financial toxicity

\section{Background}

Cervical cancer $(\mathrm{CC})$ is the 3rd most common malignancy and the 4th most common cause of cancer-related deaths in women [1]. Early stage disease can often be cured with surgery and/or chemoradiation and has a good prognosis [2]. For women with extrapelvic disease, the 5 -year survival rate is only $17 \%$. For women with recurrent disease, prognosis is even worse with 5 -year survival rates of less than 5\% [3]. Persistent infection with human papilloma virus (HPV) is an essential step in the development of most cervical cancers [4]. In the KEYNOTE-158 trial, administration of Pembrolizumab in 98 pretreated, advanced cervical cancer patients resulted in an ORR of $13.3 \%$ (95\% CI, 7.3-21.6\%) and $16.0 \%(95 \% \mathrm{CI}, 8.8-25.9 \%)$ in the whole and PD-L1-positive cohort $(n=81)$ respectively [5].

Endometrial cancer (EC) is the 5th most common malignancy in women [6]. Most ECs are diagnosed at an early stage $(75 \%)$ and only a minority of these $(2-15 \%)$ experience disease recurrence. When EC is diagnosed at late stages $(25 \%)$ or has an aggressive histology, the chance of recurrence is very high (50\%) [7]. The prognosis for patients with recurrent disease is dismal, emphasizing the high unmet need for this patient population [8]. In the phase $1 \mathrm{~b}$ KEYNOTE-028 cohort of patients with PD-L1 positive advanced EC, $13 \%$ of patients achieved a partial response and another 13\% achieved stable disease upon Pembrolizumab treatment. However, polymerase $\varepsilon$ (POLE)-mutated and microsatellite instable (MSI) EC subgroups recently demonstrated enhanced infiltration of $\mathrm{CD}^{+}, \mathrm{PD}-1^{+}$and $\mathrm{PD}-\mathrm{L}^{+}$immune cells [9-11]. Encouraging case reports with immune checkpoint blockade (ICB) provided proof of principle in both tumor subgroups [12,13] and Pembrolizumab was FDA approved for all MSI+ tumors. However, POLE-mutated and MSI EC constitute only a minority of patients with recurrent EC.

Uterine sarcomas (US) are a very rare and aggressive cancer type, comprising around 3-4\% of all uterine cancers. Standard treatment consists of surgery. The available cytotoxic therapies show very little clinical benefit, which is reflected by the 5-year survival rates, ranging from 57 to $65 \%$ for stage I disease to $9-26 \%$ for stage IV disease $[14,15]$. PD-1 blockade in uterine sarcoma has been pursued in limited numbers of patients, but without major responses [16-18].

Clearly, immunotherapy data in CC and EC are limited. Response rates of around 15\% are encouraging but not enough in this poor prognostic population. Evidence is pointing towards a crucial role of the tumor microenvironment (TME) in modulating an anti-tumor immune response, urging for combinatorial approaches to improve responses to ICB $[19,20]$.

Recent pre-clinical and clinical data indicate that the combination of radiotherapy (RT) with ICB showed acceptable toxicity $[21,22]$ and could potentiate the in situ vaccine effect of radiotherapy, mainly when given concomitant, but not sequential [23-25]. In addition, it has been described that RT induces immune cell recruitment into the tumor by releasing chemokines, thereby altering the TME [25-27].

In an attempt to further modulate the TME in an inexpensive manner, we added repurposed compounds (i.e. drugs approved for another indication) with (immune) modulating properties. The proposed mode of action of the combination is depicted in Fig. 1. Vitamin D is able to increase immune cell infiltration and reduce suppressive $\mathrm{CD}^{+} 4^{+}$cells in human tumors [28-32] and inhibits cancer stem cells $[33,34]$. Aspirin acts by counter-acting COX activity [35-37] and by favoring an overall anti-angiogenic balance [38]. Lansoprazole, a proton-pump inhibitor, is added to inhibit tumor acidosis, thereby improving intratumoral immune cell function [39-42]. Low-dose cyclophosphamide exerts immunostimulatory and antiangiogenic effects [43-45]. Curcumin is a food supplement with radiosensitizing and anti-inflammatory properties [46-48].

The current phase II trial aims at exploring the therapeutic efficacy of the combination of PD-1 blockade with RT and immune/TME modulation. Considering the unknown toxicity profile of this combination, a safety run-in is performed. Given the high economical cost of PD-1 inhibitors, it is of utmost importance to identify patients who are likely to respond to these treatments 


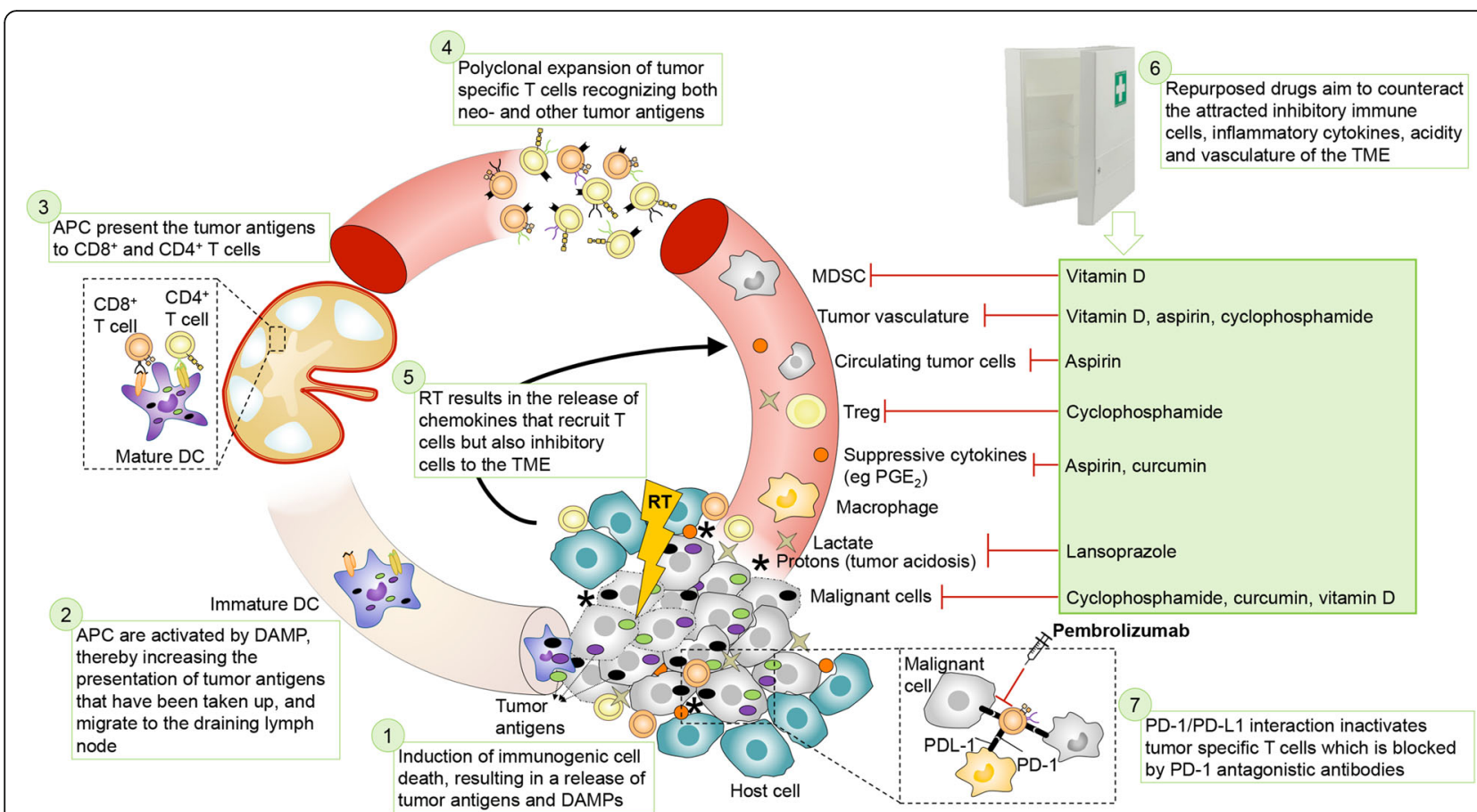

Fig. 1 Proposed mode of action of the combination treatment. (1) Immunogenic cell death, resulting in tumor antigen (TAA) release and production of danger-associated molecular patterns (DAMPs), is induced by radiation, low-dose cyclophosphamide, curcumin and vitamin D. (2) The released TAA can be taken up by immature dendritic cells (DC) for processing through the antigen processing machinery. In the presence of DAMPs, DCs will mature and (3) migrate to tumor-draining lymph nodes to prime antigen-specific CD4 ${ }^{+}$and $C D 8^{+} T$ lymphocytes. (4) The primed, tumor-specific $\mathrm{CD} 4^{+}$and $\mathrm{CD} 8^{+} \mathrm{T}$ cells enter the bloodstream and undergo clonal expansion. (5) Radiation induces chemokine secretion to recruit the tumor-specific $\mathrm{CD} 4^{+}$and $\mathrm{CD} 8^{+} \mathrm{T}$ cells into the tumor to kill tumor cells. However, these chemokines also attract inhibitory cells into the TME. (6) Primed, tumor-specific CD4 ${ }^{+}$and $C D 8^{+} T$ cells can be inhibited by several mechanisms, which we aim to counter with repurposed drugs. Tumors maintain an acidic microenvironment by the production of protons and lactate and T cells become dysfunctional in this acidic environment. Lansoprazole will induce buffering of the extracellular $\mathrm{pH}$ by inhibiting vacuolar $\mathrm{H}^{+}$-ATPase resulting in proper functioning of T cells. The tumor vasculature is abnormal, leading to hypoxic regions in which T cells become dysfunctional. Low-dose cyclophosphamide, vitamin D and aspirin will remodel the tumor vasculature to improve T cell functioning. Tumor cells release immunosuppressive cytokines, which might be exacerbated by radiation, and leads to recruitment of myeloid-derived suppressor cells (MDSC) and tumor-associated macrophages (TAM), which inhibit T cells. Aspirin and curcumin will counter some of these cytokines such as PGE $\mathrm{E}_{2}$ and vitamin D inhibits myeloid suppressive cells and IL-6, thereby improving $T$ cell function. Tumors are often infiltrated by regulatory $T$ cells (Treg) capable of inhibiting $C D 8^{+} T$ cells, which can be exacerbated by radiation. Low-dose cyclophosphamide can inhibit the suppressive activity of Treg, thereby improving the T cell response. (7) Upon activation, primed $\mathrm{CD} 4^{+}$and $\mathrm{CD} 8^{+} \mathrm{T}$ cells start to express PD-1, which can be ligated by its ligand PD-L1 on tumor cells or tumorinfiltrating immune cells, thereby limiting their effector functions. This phenomenon can be countered by pembrolizumab. Also curcumin could inhibit inflammation-mediated PD-L1. RT: radiotherapy, DAMP: danger-associated molecular pattern, APC: antigen-presenting cell, TME: tumor microenvironment, Treg: regulatory T cell, MDSC: myeloid-derived suppressor cell

beforehand. Therefore, the study is accompanied by a translational research package to evaluate immune response biomarkers in blood and tumor, characterize extracellular vesicles, explore cell death biomarkers in blood and analyze the relationship with the gut microbiome.

\section{Methods/design \\ Objectives \\ Primary objective}

To evaluate the efficacy of the treatment, which will be assessed as the objective response rate (ORR) at week 26 according to immune-related response criteria (irRC).

\section{Secondary objectives}

Safety according to Common Terminology Criteria for Adverse Events (CTCAE4.0), the ORR at week 26 according to RECIST criteria, the best overall response (BOR), progression-free survival (PFS), overall survival (OS) and quality of life (QoL).

\section{Exploratory objectives}

Exploratory objectives will be evaluated in the translational study and include evaluation of immune response biomarkers in blood and tumor biopsies, characterization of extracellular vesicles in the blood, analysis of cell death biomarkers in blood and investigation of the microbiome in feces samples (see Additional file 1). 


\section{Trial design}

The study is a Phase II multi-center, open-label, non-randomized, 3-cohort study with a safety run-in in patients with advanced and/or refractory CC, EC or US.

Even though each treatment separately has well known and tolerable safety profiles, safety of this particular combination will be determined. The safe dose is defined by 0 or 1 unmanageable dose limiting toxicity (DLT) observed in the first 6 patients within 30 days after the last RT dose irrespective of the tumor type. If 2 or more unmanageable DLTs occur, a new cohort of 6 patients will be recruited. The drug for which the adverse event is expected in the highest percentage of patients will first be adjusted in dose. If toxicity cannot be attributed to one drug, multiple drugs may become reduced in dose. Dose adjustments will continue until a safe dose is determined.

The study has an independent data safety monitoring board (DSMB) consisting of two radiotherapists, one medical oncologist, one gynecologist and one statistician. Aside from monitoring the safety, validity and integrity of the data from the study, the DSMB will evaluate the pace of recruitment and will make recommendations to the sponsor regarding the continuation, modification or termination of any or all arms of the study. Meetings will be planned every 10th patient. Bimetra Clinics, the clinical research center of the sponsor institute, will monitor this trial at several time points and at least before planned data analysis.

\section{Study population \\ Inclusion criteria}

- Histologically confirmed CC, EC or US, refractory or persistent to chemotherapy or recurrent disease after at least 1 line of chemotherapy.

- Written informed consent.

- Age 18 years or older.

- Presence of an index lesion amenable to hypofractionated RT.

- At least 1 lesion outside the RT field for clinical response assessment.

- Willing to provide tissue from a newly obtained biopsy of a tumor lesion before and after RT if technically feasible.

- ECOG Performance status 0-2.

Table 1 Adequate organ function laboratory values

\begin{tabular}{|c|c|}
\hline System & Laboratory Value \\
\hline \multicolumn{2}{|l|}{ Hematological } \\
\hline Absolute leukocyte count & $\geq 2500 / \mathrm{mcL}$ \\
\hline Absolute lymphocyte count (ALC) & $\geq 500 / \mathrm{mcL}$ \\
\hline Absolute neutrophil count (ANC) & $\geq 1500 / \mathrm{mcL}$ \\
\hline Platelets & $\geq 100,000 / \mathrm{mcL}$ \\
\hline Hemoglobin & $\begin{array}{l}\geq 9 \mathrm{~g} / \mathrm{dL} \text { or } \geq 5.6 \mathrm{mmol} / \mathrm{L} \text { without transfusion or } \\
\text { EPO dependency (within } 7 \text { days of assessment) }\end{array}$ \\
\hline \multicolumn{2}{|l|}{ Renal } \\
\hline Serum creatinine & $\leq 1.5 \times$ upper limit of normal (ULN) \\
\hline OR & OR \\
\hline $\begin{array}{l}\text { Measured or calculated }{ }^{\mathrm{a}} \text { creatinine clearance } \\
\text { (GFR can also be used in place of creatinine or } \mathrm{CrCl} \text { ) }\end{array}$ & $\begin{array}{l}\geq 60 \mathrm{~mL} / \mathrm{min} \text { for subject with creatinine } \\
\text { levels }>1.5 \mathrm{X} \text { institutional ULN }\end{array}$ \\
\hline \multicolumn{2}{|l|}{ Hepatic } \\
\hline Serum total bilirubin & $\leq 1.5 \times \cup L N$ \\
\hline OR & OR \\
\hline Direct bilirubin & $\leq$ ULN for subjects with total bilirubin levels > 1.5 ULN \\
\hline AST (SGOT) and ALT (SGPT) & $\begin{array}{l}\leq 2.5 \times \text { ULN OR } \\
\leq 5 \times \text { ULN for subjects with liver metastases }\end{array}$ \\
\hline Albumin & $>2.5 \mathrm{mg} / \mathrm{dL}$ \\
\hline \multicolumn{2}{|l|}{ Coagulation } \\
\hline International Normalized Ratio (INR) or Prothrombin Time (PT) & $\begin{array}{l}\leq 1.5 \times \text { ULN unless subject is receiving anticoagulant } \\
\text { therapyas long as PT or PTT is within therapeutic } \\
\text { range of intended use of anticoagulants }\end{array}$ \\
\hline Activated Partial Thromboplastin Time (aPTT) & $\begin{array}{l}\leq 1.5 \times \text { ULN unless subject is receiving anticoagulant therapy } \\
\text { as long as PT or PTT is within therapeutic range } \\
\text { of intended use of anticoagulants }\end{array}$ \\
\hline
\end{tabular}


- Patients treated with a proton pump inhibitor or anti-coagulant should switch to the study regimen during the trial.

- Demonstrate adequate organ function as defined in Table 1.

- Female subjects of childbearing potential should have a negative pregnancy test and must use contraception.

\section{Exclusion criteria}

- Currently participating or has participated in a study of an investigational agent within 4 weeks of the first dose of treatment.

- Diagnosis of immunodeficiency or receiving immunosuppressive therapy

- Prior chemotherapy, targeted small molecule/ antibody therapy, hormonal therapy or radiation therapy within 4 weeks prior to study.

- Known additional malignancy that requires active treatment.

- Known active central nervous system (CNS) metastases and/or carcinomatous meningitis.

- Active autoimmune disease.

- History or evidence of active, non-infectious pneumonitis.

- Active infection requiring systemic therapy.

- Prior therapy with an anti-PD-1, anti-PD-L1, or anti-PD-L2 agent.
- Known history of TB (Bacillus Tuberculosis), Human Immunodeficiency Virus (HIV), Human T cell Lymphotropic Virus (HTLV), syphilis, Hepatitis B or Hepatitis C.

- Subjects have received a live vaccine within 30 days of planned start of study therapy.

\section{Treatments and interventions Treatments}

The treatment consists of an induction phase where patients receive the combination of immune-modulatory repurposed drugs (vitamin D, aspirin, lansoprazole), metronomic chemotherapy (low-dose cyclophosphamide) and the food supplement (curcumin) for 2 weeks. Thereafter, the first dose of pembrolizumab $(200 \mathrm{mg})$ is administered before the first hypofractionated RT (8 Gy) to 1 index lesion. RT is given twice $(8 \mathrm{~Gy})$ more with a 48-h interval. RT details are described in the Additional file 1. Pembrolizumab $(200 \mathrm{mg})$ is repeated every 3 weeks for a total of 6 cycles. The immune-modulatory combination is given continuously until week 26 , the time of primary endpoint measurement. A detailed overview can be found in the study scheme (Fig. 2). Patients with clinical benefit (SD, PR, CR as BOR) can continue pembrolizumab (200 mg, Q3W) for up to 2 years, according to article 34 of the Declaration of Helsinki on post-trial access to study medication. Treatment with the immunomodulatory cocktail may be continued upon investigators' choice. To aid patient adherence to this complex

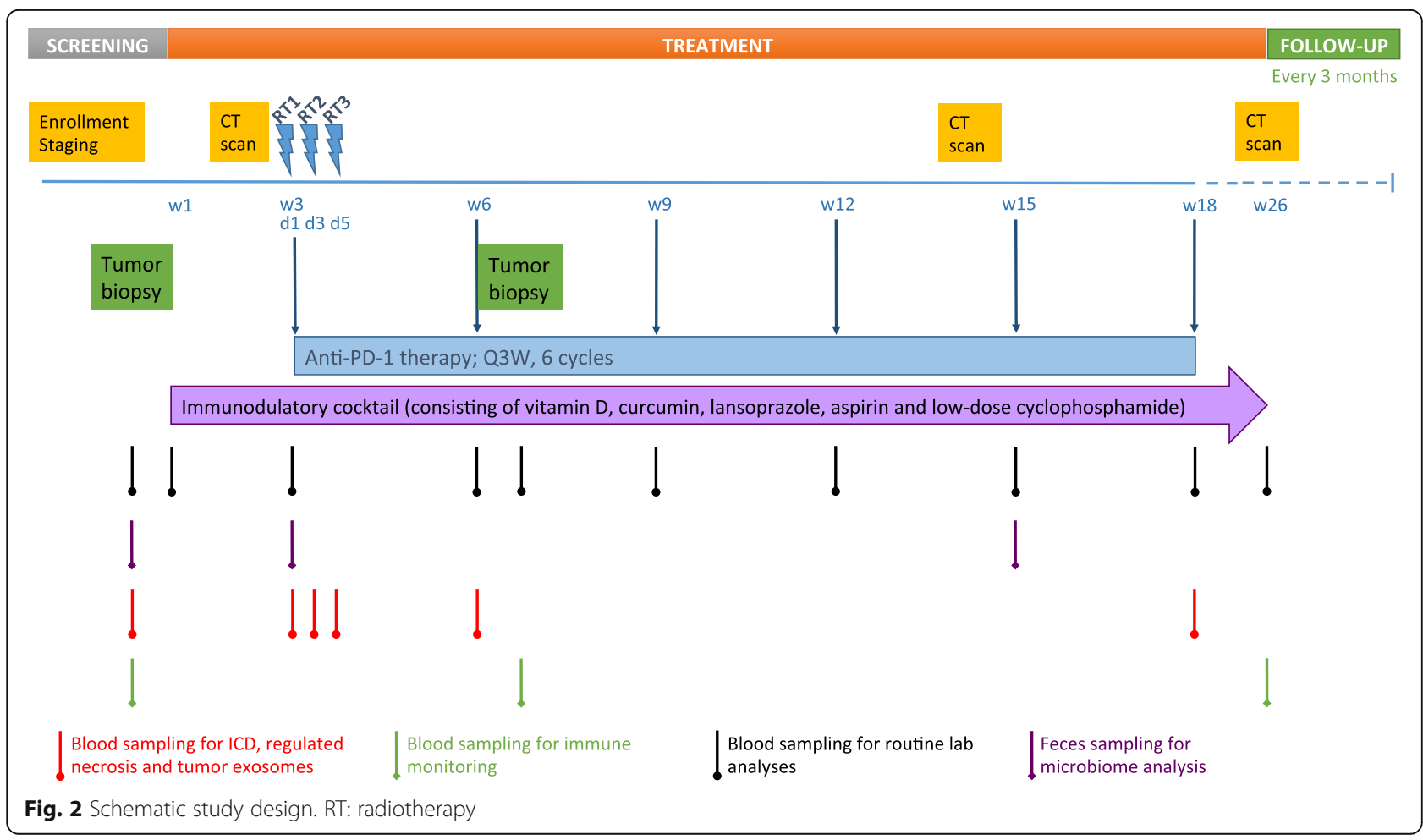


treatment, patients receive a diary and only sufficient medication is provided until the next hospital visit. Concerning the immune-modulatory combination, we opted to add an extra drug or food supplement every $24 \mathrm{~h}$ until the complete combination is taken during the first week of the induction phase for safety reasons. Thereafter, the combination is taken as described in the treatment schedule (Table 2).

Table 2 Trial treatment schedule

\begin{tabular}{|c|c|c|c|c|c|c|c|c|c|}
\hline \multirow[t]{2}{*}{ Drug } & \multirow[t]{2}{*}{ Dose/Potency } & \multirow[t]{2}{*}{ Frequency } & \multicolumn{4}{|c|}{$\begin{array}{l}\text { Time of oral } \\
\text { intake }\end{array}$} & \multirow[t]{2}{*}{$\begin{array}{l}\text { Route of } \\
\text { Administration }\end{array}$} & \multirow[t]{2}{*}{ Treatment Period } & \multirow[t]{2}{*}{ Remarks } \\
\hline & & & $\begin{array}{l}8 \\
h\end{array}$ & $\begin{array}{l}12 \\
h\end{array}$ & $\begin{array}{l}18 \\
h\end{array}$ & $\begin{array}{l}20 \\
h\end{array}$ & & & \\
\hline $\begin{array}{l}\text { Pembrolizumab } \\
\text { (Keytruda) }\end{array}$ & 200 mg & Q3W & & & & & IV infusion & $\begin{array}{l}\text { Day } 1 \text { of each 3-week } \\
\text { cycle }\end{array}$ & $\begin{array}{l}\text { May be discontinued upon } \\
\text { unacceptable toxicity } \\
\text { Administration should be } \\
\text { withheld for drug-related } \\
\text { non-hematologic toxicity } \geq \\
\text { grade } 2 \text { (excluding fatigue) } \\
\text { Use corticosteroids for irAE }\end{array}$ \\
\hline Radiation & 8 Gy & $\begin{array}{l}3 \text { fractions } \\
48 \mathrm{~h} \text { apart }\end{array}$ & & & & & & $\begin{array}{l}\text { Day } 1,3 \text { and } 5 \text { of } \\
\text { Pembrolizumab cycle } 1\end{array}$ & See Additional file 1 \\
\hline Vitamin D3 (D-Cure) & $2000 \mathrm{IU}(50 \mu \mathrm{g})^{\mathrm{a}}$ & Daily & & & $x$ & & Oral & Daily from day -14 & $\begin{array}{l}\text { Intake of other vitamin D } \\
\text { preparations should be } \\
\text { stopped } \\
\text { Blood should be monitored } \\
\text { for calcium and phosphate } \\
\text { Caution in patients } \\
\text { receiving digitalis } \\
\text { preparations }\end{array}$ \\
\hline $\begin{array}{l}\text { Lansoprazole } \\
\text { (Lansoprazole Teva) }\end{array}$ & $\begin{array}{l}180 \mathrm{mg} \text { (uneven } \\
\text { weeks); } \\
30 \mathrm{mg} \\
\text { (even weeks) }^{\mathrm{b}}\end{array}$ & Daily & & $x$ & & $x^{c}$ & Oral & Daily from day -12 & $\begin{array}{l}\text { Needs to be taken at least } \\
30 \text { min before a meal } \\
\text { Patients taking any kind of } \\
\text { proton pump inhibitors } \\
\text { should switch to Lansoprazole } \\
\text { Teva throughout the study } \\
\text { period } \\
\text { Must be taken } 2 \mathrm{~h} \text { apart from } \\
\text { all other orally administered } \\
\text { drugs }\end{array}$ \\
\hline Aspirin (Sedergine) & $325 \mathrm{mg}^{\mathrm{d}}$ & Daily & $x$ & & & & Oral & Daily from day -11 & $\begin{array}{l}\text { Patients receiving any other } \\
\text { anti-coagulant therapy should } \\
\text { switch to Sedergine throughout } \\
\text { the study }\end{array}$ \\
\hline $\begin{array}{l}\text { Cyclophosphamide } \\
\text { (Endoxan) }\end{array}$ & $50 \mathrm{mg}{ }^{e}$ & Daily & $x$ & & & & Oral & Daily from day -10 & $\begin{array}{l}\text { Monitor leukocyte levels } \\
\text { regularly during treatment } \\
\text { Do not administer to patients } \\
\text { with leukocyte levels }<2500 / \mu l \\
\text { and/or thrombocyte levels } \\
\text { of }<50,000 / \mu l \\
\text { Consumption of grapefruit and } \\
\text { its derivatives is counter-advised }\end{array}$ \\
\hline $\begin{array}{l}\text { Curcumin (CurcuPhyt) } \\
\text { (Food supplement, NIMP) }\end{array}$ & $2 g^{f}$ & Daily & $x$ & & $x$ & & Oral & Daily from day -13 & $\begin{array}{l}\text { Patients are suggested to } \\
\text { not take } \mathrm{H} 2 \\
\text { Beta blockers } \\
\text { (beta-adrenoreceptor } \\
\text { antagonists) } \\
\text { Proton pump inhibitors } \\
\text { should be } \\
\text { consumed } 2 \mathrm{~h} \text { apart } \\
\text { Patients should not consume } \\
\text { other turmeric containing food }\end{array}$ \\
\hline
\end{tabular}

\footnotetext{
a 30 drops should be resolved in fat-containing drink, e.g. milk

${ }^{\mathrm{b}}$ Capsules should be swallowed entirely with fluid

c uneven weeks only

d Effervescent tablets should be dissolved in water

e Tablets should be taken with a large amount of fluid.

${ }^{f}$ Capsules should be taken with a meal and not be chewed on
} 


\section{Interventions}

The study flow chart (Fig. 2 and Additional file 1: Table S1) tabulates the timing of all scheduled drug administrations, blood samplings and tumor imaging procedures throughout the study to document safety and efficacy of the treatment.

For the exploratory translational research, blood, biopsy and feces collections take place at different time points during the study.

The details of the exploratory translational research analyses are described in detail in the Additional file 1.

\section{Sample size}

The total sample size consists of both evaluable and non-evaluable patients. Evaluable patients are defined as patients who received at least all components of the treatment, being 2 weeks of immunomodulatory combination, 1 dose of pembrolizumab and the 3 radiotherapy fractions. The study will continue until the necessary number of evaluable patients is reached. Patients included in the safety run-in will be part of the efficacy analysis to fasten inclusion. However, each cohort will be analyzed separately and no comparison between disease types will be made. The sample size is calculated based on a two-stage design using exact binomial tests. Estimated numbers of $\mathrm{CC}$ and EC patients needed to achieve the primary study objective and the clinical and statistical assumptions made can be found in Table 3. For the US group, no sample size calculation is performed due to the rarity of the disease. However, to provide these patients with a possibly effective treatment option, these patients will be allowed on study. These data will provide an indication for possible further development of this treatment in uterine sarcoma.

\section{Data analysis}

The CC and EC groups will be analyzed separately. No correction for multiple testing will be applied. Only descriptive statistics will be provided for the uterine sarcoma group.

\section{Primary endpoint}

Patients with complete or partial response at week 26 according irRC criteria will be regarded as responders. Patients for whom the scheduled tumor imaging at week
26 is not available will be considered to be a non-responder for the primary analysis.

The null hypothesis that the true response rate $\pi$ is $10 \%$ will be tested against a one-sided alternative (Ha: $\pi>10 \%)$. A point estimate with a $90 \%$ confidence interval will be reported.

\section{Secondary endpoints}

Safety The number of unmanageable dose limiting toxicities will be reported for the run-in period and the main trial. The number of patients with AEs, serious AEs (SAEs) and treatment-related AEs will be summarized by system organ class and preferred term and by worst toxicity grade. Laboratory safety and other safety assessments will be described descriptively by visit and the difference with the baseline visit for all other visits for each group separately.

Response rate at week 26 according to RECIST The ORR at week 26 according to RECIST will be analyzed similarly as the primary endpoint.

Best overall response The BOR is defined as the best response (confirmed complete or partial response, per RECIST v1.1) recorded from the start of the study treatment at any time during the study taking into account any requirement for confirmation. It will be analyzed similarly as the primary endpoint.

Progression-free survival The PFS, defined as the time from start of treatment until progression or last follow-up, will be analyzed as interval censored data by means of the Turnbull estimate. Patients without progression will be censored at their last visit. At weeks 26, 52, 75, 104, 130 and 156 the proportion of progression-free patients will be estimated with a 95\% confidence interval and median PFS will be calculated.

Overall survival The OS, defined as the time from start of treatment until death, will be analyzed by means of a Kaplan-Meier estimate. Patients who survived will be censored at their last visit. At weeks 26, 52, 75, 104, 130 and 156 the proportion of patients surviving will be

Table 3 Statistical sample size calculation

\begin{tabular}{|c|c|c|c|c|c|c|}
\hline & $\begin{array}{l}\text { Null hypothesis } \\
\left(\mathrm{H}_{0}\right)\end{array}$ & $\begin{array}{l}\text { Total number of patients } \\
\text { required }\end{array}$ & $\begin{array}{l}\text { Number of responses needed for } \mathrm{HO} \\
\text { rejection }\end{array}$ & $\begin{array}{l}\text { Alternative } \\
\text { hypothesis }\end{array}$ & $\begin{array}{l}\text { Type I } \\
\text { error }\end{array}$ & power \\
\hline Cervical cancer & $\pi>10 \%$ & 18 & 5 & $\pi=35 \%$ & $5 \%$ & $80 \%$ \\
\hline $\begin{array}{l}\text { Endometrial } \\
\text { carcinoma }\end{array}$ & $\pi>10 \%$ & 25 & 6 & $\pi=30 \%$ & $5 \%$ & $79.3 \%$ \\
\hline Uterine sarcoma & \multicolumn{6}{|c|}{ No sample size calculation is performed due to the rarity of the disease, but these patients will be allowed on the study } \\
\hline
\end{tabular}


estimated with a 95\% confidence interval and median OS will be calculated.

Quality of life Quality of life will be measured by FACT-Cx questionnaire for the $\mathrm{CC}$ group and by the FACT-G questionnaire for the EC and US groups. Descriptive statistics of the total score at each visit and the difference with the baseline visit for all other visits will be reported.

\section{Exploratory endpoints}

The explorative endpoints will be described descriptively by visit and the difference with the baseline visit for all other visits for each group separately. They will be related to the primary endpoint, ORR at week 26 according to RECIST, BOR, PFS and OS.

\section{Subgroup analyses}

For all primary and secondary endpoints subgroup analysis is planned. This is exploratory and not statistically powered. For CC, squamous versus non-squamous histology, HPV-positive versus HPV-negative tumors and PD-L1 status will be evaluated. For EC, endometroid versus non-endometroid histology, grade 1 versus grade $2 / 3$ tumors, MSI versus MSS, hormone receptor positive versus negative, PTEN deficient versus wild-type, and wild-type POLE versus proofreading mutant POLE status will be analyzed. For both CC and EC, correlation with absolute lymphocyte count before treatment and at 0,1 and 3 months after the first pembrolizumab administration will be evaluated. Subgroup analysis is based on the etiology of each cancer type.

Comparison for all primary and secondary endpoints between the subgroups will be done by a Fisher's Exact test.

Comparison for PFS between the subgroups will be done by means of the generalized logrank test of Sun.

Comparison for OS between the subgroups will be done by means of the logrank test.

\section{Discussion}

Although ICB has led to remarkable response rates in some subtypes of uterine cancers, the majority of patients with recurrent CC, EC or US do not benefit from single-agent ICB, urging for the development of more effective therapeutic regimens for these patients. We hypothesize that combining PD-1 blockade with radiotherapy and additional immune modulators might result in clinical responses in about one third of patients. The combination with repurposed compounds is also of important economical value, as opposed to combinations with novel, expensive drugs that are posing financial toxicity to the healthcare systems [49-53]. In the current study, we aim to assess the efficacy of this novel combination treatment in recurrent CC, EC and US. The innovation of this study originates from the combined use of 7 treatments to simultaneously act on tumor metabolism, angiogenesis and anti-tumor immunity. In addition, the translational research focused on immunologic markers, extracellular vesicles, cell death biomarkers and alterations in the gut microbiome might be suitable to identify mechanisms of response and resistance to therapy, resulting in predictive biomarkers for efficacy and improved patient selection in future clinical applications.

\section{Additional file}

Additional file 1: 1. Additional data. 2. Additional Tables. Table S1: Trial flowchart. Table S2: Planned immunological analyses. (DOCX 95 kb)

\section{Abbreviations}

ACTH: Adrenocorticotropic hormone; AE: Adverse event; ALC: Absolute lymphocyte count; ALT: Alanine aminotransferase; ANA: Anti-nuclear antibodies; ANC: Absolute neutrophil count; APC: Antigen-presenting cell; aPTT: Activated partial thromboplastin time; AST: Aspartate aminotransferase; BOR: Best overall response; CBC: Complete blood count; CNS: Central nervous system; COX: Cyclooxygenase; CR: Complete response; CRP: Creactive protein; CT: Computer tomography; CTCAE: Common Terminology Criteria for Adverse Events; CY: Cyclophosphamide; DAMPs: Dangerassociated molecular patterns; DC: Dendritic cell; DLT: Dose limiting toxicity; DSMB: Data safety monitoring board; EC: Endometrial cancer;

ECG: Electrocardiogram; ECOG: Eastern cooperative oncology group; EPO: Erythropoietin; FDA: Food and drug administration; GFR: Glomerular filtration rate; Gy: Gray; HCG: Human choriongonadotrophin; HCV: Hepatitis C virus; HIV: Human immunodeficiency virus; HPV: Human papilloma virus; HTLV: Human T cell Lymphotropic Virus; ICB: Immune checkpoint blockade; IL: Interleukin; INR: International normalized ratio; irAE: Immune-related adverse event; irRC: Immune-related response criteria; LDH: Lactate dehydrogenase; LH: Luteinizing hormone; mAb: Monoclonal antibody; MDSC: Myeloid-derived suppressor cells; MSI: Microsatellite instable; MSS: Microsatellite stable; NIMP: Non-investigational medicinal product; ORR: Overall response rate; OS: Overall survival; PD: Programmed death; PDL: Programmed death ligand; PFS: Progression-free survival;

PGE: Prostaglandin E; POLE: Exonuclease domain of polymerase $\varepsilon_{;}$PR: Partial response; PT: Prothrombin time; PTEN: Phosphatase and tensin homolog; Q3W: Every 3 weeks; QoL: Quality of life; RECIST: Response Evaluation Criteria in Solid Tumors; RT: Radiotherapy; SAE: Serious adverse event; SD: Stable disease; SGOT: Serum glutamic oxaloacetic transaminase; SGPT: Serum glutamic pyruvic transaminase; TAA: Tumor-associated antigen; TAM: Tumorassociated macrophages; TB: Tuberculosis bacillus; TIL: Tumor-infiltrating lymphocyte; TME: Tumor microenvironment; TPO: Thyreoperoxidase; Treg: Regulatory T cells; TSH: Thyroid stimulating hormone; TSI: Thyroidstimulating immunoglobulin; ULN: Upper limit of normal

\section{Acknowledgements}

We thank MSD for providing Pembrolizumab and Nutrisan NV for providing CurcuPhyt free of charge for this study. Katrien Vandecasteele holds a mandate for clinical and translational research from the Foundation against Cancer.

\section{Funding}

The study is funded by "Kom op tegen Kanker (Stand up to Cancer), the Flemish cancer society", the Anticancer Fund and the National Lottery of Belgium. The Anticancer Fund is also involved in the design of the study and writing the manuscript.

Availability of data and materials Not applicable. 


\section{Authors' contributions}

$\mathrm{ST}, \mathrm{AV}, \mathrm{KV}$ and $\mathrm{HD}$ designed the protocol. $\mathrm{HD}$ is the principal investigator of the study. ST, AV, EN, LL, ED, KV and HD prepared the manuscript. PVD, PV, $A D, S A$ and $P D$ revised the manuscript. ST, AV, FA, KV and $H D$ are responsible for interpretation of the data. EN, PVD, PV, AD, SA, PD, KV and HD are responsible for patient recruitment. KV is responsible for the radiotherapy treatments. ST coordinates the collection of biological samples for the study's translational endpoints. ST, LL and ED are responsible for the translational study. All authors read and approved the final manuscript.

\section{Ethics approval and consent to participate}

This study obtained approval from the Belgian Federal Agency for Medicines and Health Products (FAHMP) and from the Ethics Committee of the Sponsor, Ghent University Hospital (UZ Ghent, reference number 2017/0304), the Ethics Committee of Universitair Ziekenhuis Antwerpen/Universiteit Antwerpen, the Ethics Committee of Institut Jules Bordet, Le Comité d'Ethique de Clinique et Maternité Sainte Elisabeth and Comité d'Ethique Hospitalo-Facultaire Saint-Luc - UCL. The study is conducted in accordance with the Helsinki Declaration, the International Conference of Harmonization Good Clinical Practice guidelines, and local regulatory requirements. Written informed consent will be obtained from each patient.

\section{Consent for publication}

Not applicable.

\section{Competing interests}

The authors declare that they have no competing interests.

\section{Publisher's Note}

Springer Nature remains neutral with regard to jurisdictional claims in published maps and institutional affiliations.

\begin{abstract}
Author details
'Division of Gynecologic Oncology, Department of Oncology, KU Leuven, Leuven, Belgium. ${ }^{2}$ Leuven Cancer Institute (LKI), Leuven, Belgium. ${ }^{3}$ Anticancer Fund, Strombeek-Bever, Belgium. ${ }^{4}$ Division of Medical Oncology, UZ Gent, Ghent, Belgium. ${ }^{5}$ Cancer Research Institute Gent (CRIG), Ghent, Belgium. ${ }^{6}$ Division of Gynecologic Oncology and Senology, University Hospital Antwerp, Antwerp, Belgium. ${ }^{7}$ Division of Oncology, CHU UCL Namur, Sainte Elisabeth, Namur, Belgium. ${ }^{8}$ Division of Radiation Oncology, Institut Jules Bordet, Brussels, Belgium. ${ }^{9}$ Division of Radiation Oncology, Iridium Cancer Network, Antwerp, Belgium. ${ }^{10}$ Division of Molecular Imaging, Pathology, Radiotherapy \& Oncology (MIPRO), University of Antwerp, Antwerp, Belgium. ${ }^{11}$ Division of Gynecology \& Obstetrics, UZ Leuven, Leuven, Belgium. ${ }^{12}$ Center for Gynecologic Oncology Amsterdam (CGOA), Amsterdam, the Netherlands. ${ }^{13}$ Division of Radiation Oncology, UZ Gent, Ghent, Belgium.
\end{abstract}

\section{Received: 8 March 2019 Accepted: 3 May 2019}

Published online: 28 May 2019

\section{References}

1. Torre LA, Bray F, Siegel RL, Ferlay J, Lortet-Tieulent J, Jemal A. Global cancer statistics, 2012. CA Cancer J Clin. 2015;65:87-108

2. Marth C, Landoni F, Mahner S, McCormack M, Gonzalez-Martin A, Colombo $\mathrm{N}$, Committee EG. Cervical cancer: ESMO clinical practice guidelines for diagnosis, treatment and follow-up. Ann Oncol. 2017;28:iv72-83.

3. Howlader N, Noone AM, Krapcho M, Miller D, Bishop K, Altekruse SF, Kosary CL, Yu M, Ruhl J, Tatalovich Z, Mariotto A, Lewis DR, Chen HS, Feuer EJ, Cronin KA (eds). SEER Cancer Statistics Review, 1975-2013, National Cancer Institute. Bethesda, MD, https://seer.cancer.gov/archive/csr/1975_2013/, based on November 2015 SEER data submission, posted to the SEER web site, April 2016.

4. zur Hausen H. Papillomaviruses in the causation of human cancers - a brief historical account. Virology. 2009;384:260-5.

5. Chung HC, Schellens JHM, Delord J-P, Perets R, Italiano A, Shapira-Frommer R, Manzuk L, Piha-Paul SA, Wang J, Zeigenfuss S, et al. Pembrolizumab treatment of advanced cervical cancer: updated results from the phase 2 KEYNOTE-158 study. J Clin Oncol. 2018;36:abstract 5522.

6. Ferlay J, Soerjomataram I, Dikshit R, Eser S, Mathers C, Rebelo M, Parkin DM, Forman D, Bray F. Cancer incidence and mortality worldwide: sources, methods and major patterns in GLOBOCAN 2012. Int J Cancer. 2015;136: E359-86.

7. Salani R, Backes FJ, Fung MF, Holschneider CH, Parker LP, Bristow RE, Goff BA. Posttreatment surveillance and diagnosis of recurrence in women with gynecologic malignancies: Society of Gynecologic Oncologists recommendations. Am J Obstet Gynecol. 2011;204:466-78.

8. Garg G, Mutch DG. Treatment Strategies and Prognosis of Endometrial Cancer. In: Saldivar JS, editor. Cancer of the Uterine Endometrium Advances and Controversies. London: InTech; 2012. Available from: https:// www.intechopen.com/books/cancer-of-the-uterine-endometrium-advancesand-controversies/treatment-strategies-and-prognosis-in-endometrial-cancer

9. Eggink FA, Van Gool IC, Leary A, Pollock PM, Crosbie EJ, Mileshkin L, Jordanova ES, Adam J, Freeman-Mills L, Church DN, et al. Immunological profiling of molecularly classified high-risk endometrial cancers identifies POLE-mutant and microsatellite unstable carcinomas as candidates for checkpoint inhibition. Oncoimmunology. 2017;6:e1264565.

10. Howitt BE, Shukla SA, Sholl LM, Ritterhouse LL, Watkins JC, Rodig S, Stover E, Strickland KC, D'Andrea AD, Wu CJ, et al. Association of Polymerase emutated and microsatellite-instable endometrial cancers with Neoantigen load, number of tumor-infiltrating lymphocytes, and expression of PD-1 and PD-L1. JAMA Oncol. 2015;1(9):1319-23.

11. van Gool IC, Eggink FA, Freeman-Mills L, Stelloo E, Marchi E, de Bruyn M, Palles C, Nout RA, de Kroon CD, Osse EM, et al. POLE proofreading mutations elicit an antitumor immune response in endometrial Cancer. Clin Cancer Res. 2015;21:3347-55.

12. Santin AD, Bellone S, Buza N, Choi J, Schwartz PE, Schlessinger J, Lifton RP. Regression of chemotherapy-resistant polymerase epsilon (POLE) ultramutated and MSH6 hyper-mutated endometrial tumors with Nivolumab. Clin Cancer Res. 2016;22:5682-7.

13. Mehnert JM, Panda A, Zhong H, Hirshfield K, Damare S, Lane K, Sokol L, Stein MN, Rodriguez-Rodriquez L, Kaufman HL, et al. Immune activation and response to pembrolizumab in POLE-mutant endometrial cancer. J Clin Invest. 2016;126:2334-40.

14. Chern JY, Boyd LR, Blank SV. Uterine sarcomas: the latest approaches for these rare but potentially deadly tumors. Oncology (Williston Park). 2017;31: 229-36.

15. Cuppens T, Depreeuw J, Annibali D, Thomas D, Hermans E, Gomme E, Trinh XB, Debruyne D, Moerman P, Lambrechts D, Amant F. Establishment and characterization of uterine sarcoma and carcinosarcoma patient-derived xenograft models. Gynecol Oncol. 2017;146:538-45.

16. Paoluzzi L, Cacavio A, Ghesani M, Karambelkar A, Rapkiewicz A, Weber J, Rosen G. Response to anti-PD1 therapy with nivolumab in metastatic sarcomas. Clin Sarcoma Res. 2016;6:24.

17. George S, Miao D, Demetri GD, Adeegbe D, Rodig SJ, Shukla S, Lipschitz M, Amin-Mansour A, Raut CP, Carter SL, et al. Loss of PTEN is associated with resistance to anti-PD-1 checkpoint blockade therapy in metastatic uterine Leiomyosarcoma. Immunity. 2017;46:197-204.

18. Ben-Ami E, Barysauskas CM, Solomon S, Tahlil K, Malley R, Hohos M, Polson K, Loucks M, Severgnini M, Patel T, et al. Immunotherapy with single agent nivolumab for advanced leiomyosarcoma of the uterus: results of a phase 2 study. Cancer. 2017;123:3285-90.

19. Tumeh PC, Harview CL, Yearley JH, Shintaku IP, Taylor EJ, Robert L, Chmielowski B, Spasic M, Henry G, Ciobanu V, et al. PD-1 blockade induces responses by inhibiting adaptive immune resistance. Nature. 2014;515:568-71.

20. Smyth MJ, Ngiow SF, Ribas A, Teng MW. Combination cancer immunotherapies tailored to the tumour microenvironment. Nat Rev Clin Oncol. 2016;13:143-58

21. Luke JJ, Lemons JM, Karrison TG, Pitroda SP, Melotek JM, Zha Y, Al-Hallaq HA, Arina A, Khodarev NN, Janisch L, et al. Safety and clinical activity of Pembrolizumab and multisite stereotactic body radiotherapy in patients with advanced solid tumors. J Clin Oncol. 2018;36:1611-8.

22. Kroeze SG, Fritz C, Hoyer M, Lo SS, Ricardi U, Sahgal A, Stahel R, Stupp R, Guckenberger M. Toxicity of concurrent stereotactic radiotherapy and targeted therapy or immunotherapy: a systematic review. Cancer Treat Rev. 2017;53:25-37.

23. Teng F, Kong L, Meng X, Yang J, Yu J. Radiotherapy combined with immune checkpoint blockade immunotherapy: achievements and challenges. Cancer Lett. 2015;365:23-9.

24. Dovedi SJ, Adlard AL, Lipowska-Bhalla G, McKenna C, Jones S, Cheadle EJ, Stratford IJ, Poon E, Morrow M, Stewart R, et al. Acquired resistance to 
fractionated radiotherapy can be overcome by concurrent PD-L1 blockade. Cancer Res. 2014;74:5458-68.

25. Vatner RE, Cooper BT, Vanpouille-Box C, Demaria S, Formenti SC. Combinations of immunotherapy and radiation in cancer therapy. Front Oncol. 2014;4:325.

26. Ahmed MM, Hodge JW, Guha C, Bernhard EJ, Vikram B, Coleman CN. Harnessing the potential of radiation-induced immune modulation for cancer therapy. Cancer Immunol Res. 2013;1:280-4.

27. Barker HE, Paget JT, Khan AA, Harrington KJ. The tumour microenvironment after radiotherapy: mechanisms of resistance and recurrence. Nat Rev Cancer. 2015;15:409-25.

28. Zhuravel E, Efanova O, Shestakova T, Glushko N, Mezhuev O, Soldatkina M, Pogrebnoy P. Administration of vitamin D3 improves antimetastatic efficacy of cancer vaccine therapy of Lewis lung carcinoma. Exp Oncol. 2010;32:33-9.

29. Walsh JE, Clark AM, Day TA, Gillespie MB, Young MR. Use of alpha,25dihydroxyvitamin D3 treatment to stimulate immune infiltration into head and neck squamous cell carcinoma. Hum Immunol. 2010;71:659-65.

30. Kulbersh JS, Day TA, Gillespie MB, Young MR. 1alpha,25-Dihydroxyvitamin $\mathrm{D}(3)$ to skew intratumoral levels of immune inhibitory CD34(+) progenitor cells into dendritic cells. Otolaryngol Head Neck Surg. 2009:140:235-40.

31. Lathers DM, Clark Jl, Achille NJ, Young MR. Phase 1B study to improve immune responses in head and neck cancer patients using escalating doses of 25-hydroxyvitamin D3. Cancer Immunol Immunother. 2004;53:422-30.

32. Lathers DM, Clark II, Achille NJ, Young MR. Phase IB study of 25hydroxyvitamin $\mathrm{D}(3)$ treatment to diminish suppressor cells in head and neck cancer patients. Hum Immunol. 2001;62:1282-93.

33. So JY, Suh N. Targeting cancer stem cells in solid tumors by vitamin D. J Steroid Biochem Mol Biol. 2015;148:79-85.

34. Jeong $Y$, Swami S, Krishnan AV, Williams JD, Martin S, Horst RL, Albertelli MA, Feldman BJ, Feldman D, Diehn M. Inhibition of mouse breast tumorinitiating cells by calcitriol and dietary vitamin D. Mol Cancer Ther. 2015;14: 1951-61.

35. Liao Z, Mason KA, Milas L. Cyclo-oxygenase-2 and its inhibition in cancer: is there a role? Drugs. 2007;67:821-45.

36. Zelenay S, van der Veen AG, Bottcher JP, Snelgrove K, Rogers N, Acton SE, Chakravarty P, Girotti MR, Marais R, Quezada SA, et al. Cyclooxygenasedependent tumor growth through evasion of immunity. Cell. 2015;162: 1257-70.

37. Hamada T, Giannakis M, Ogino S. Aspirin in the era of immunotherapy. Oncotarget. 2017:8:73370-1.

38. Holmes CE, Jasielec J, Levis JE, Skelly J, Muss HB. Initiation of aspirin therapy modulates angiogenic protein levels in women with breast cancer receiving tamoxifen therapy. Clin Transl Sci. 2013;6:386-90.

39. Corbet C, Feron O. Tumour acidosis: from the passenger to the driver's seat. Nat Rev Cancer. 2017;17:577-93.

40. Lu ZN, Tian B, Guo XL. Repositioning of proton pump inhibitors in cancer therapy. Cancer Chemother Pharmacol. 2017;80(5):925-37. https://doi.org/ 10.1007/s00280-017-3426-2

41. Bellone M, Calcinotto A, Filipazzi P, De Milito A, Fais S, Rivoltini L. The acidity of the tumor microenvironment is a mechanism of immune escape that can be overcome by proton pump inhibitors. Oncoimmunology. 2013;2: e22058.

42. Calcinotto A, Filipazzi P, Grioni M, lero M, De Milito A, Ricupito A, Cova A, Canese $\mathrm{R}$, Jachetti $\mathrm{E}$, Rossetti $\mathrm{M}$, et al. Modulation of microenvironment acidity reverses anergy in human and murine tumor-infiltrating $T$ lymphocytes. Cancer Res. 2012;72:2746-56.

43. Penel N, Adenis A, Bocci G. Cyclophosphamide-based metronomic chemotherapy: after 10 years of experience, where do we stand and where are we going? Crit Rev Oncol Hematol. 2012;82:40-50.

44. Sistigu A, Viaud S, Chaput N, Bracci L, Proietti E, Zitvogel L. Immunomodulatory effects of cyclophosphamide and implementations for vaccine design. Semin Immunopathol. 2011;33:369-83.

45. Scurr MJ, Pembroke T, Bloom A, Roberts DJ, Thomson A, Smart K, Bridgeman $\mathrm{H}$, Adams RA, Brewster AE, Jones R, et al. Low-dose cyclophosphamide induces anti-tumor T-cell responses which associate with survival in metastatic colorectal cancer. Clin Cancer Res. 2017;23(22): 6771-80. https://doi.org/10.1158/1078-0432.CCR-17-0895.

46. Shehzad A, Park JW, Lee J, Lee YS. Curcumin induces radiosensitivity of in vitro and in vivo cancer models by modulating pre-mRNA processing factor 4 (Prp4). Chem Biol Interact. 2013;206:394-402.
47. Basnet $\mathrm{P}$, Skalko-Basnet N. Curcumin: an anti-inflammatory molecule from a curry spice on the path to cancer treatment. Molecules. 2011;16:4567-98.

48. Lim SO, Li CW, Xia W, Cha JH, Chan LC, Wu Y, Chang SS, Lin WC, Hsu JM, Hsu YH, et al. Deubiquitination and stabilization of PD-L1 by CSN5. Cancer Cell. 2016;30:925-39.

49. Prasad V, De Jesus K, Mailankody S. The high price of anticancer drugs: origins, implications, barriers, solutions. Nat Rev Clin Oncol. 2017;14:381-90.

50. Kaiser J. Too much of a good thing? Science. 2018:359:1346-7.

51. Mailankody S, Prasad V. Five years of Cancer drug approvals: innovation, efficacy, and costs. JAMA Oncol. 2015;1:539-40.

52. van Harten WH, Wind A, de Paoli P, Saghatchian M, Oberst S. Actual costs of cancer drugs in 15 European countries. Lancet Oncol. 2016;17:18-20.

53. Kantarjian H, Steensma D, Rius Sanjuan J, Elshaug A, Light D. High cancer drug prices in the United States: reasons and proposed solutions. J Oncol Pract. 2014;10:e208-11.

\section{Ready to submit your research? Choose BMC and benefit from:}

- fast, convenient online submission

- thorough peer review by experienced researchers in your field

- rapid publication on acceptance

- support for research data, including large and complex data types

- gold Open Access which fosters wider collaboration and increased citations

- maximum visibility for your research: over $100 \mathrm{M}$ website views per year

At BMC, research is always in progress.

Learn more biomedcentral.com/submissions 